\title{
A PROFISSIONALIDADE DOCENTE EM UMA ABORDAGEM CONSTRUTIVISTA
}

\author{
CILENE RIBEIRO DE SÁ LEITE CHAKUR \\ Faculdade de Ciências e Letras da Universidade Estadual Paulista de Araraquara \\ chakur@fclar.unesp.br
}

\begin{abstract}
RESUMO
Este trabalho contrapõe-se, de um lado, a investigações cognitivistas que mostram imprecisões conceituais e exaltações exageradas da capacidade de reflexão e autonomia do professor e, de outro, a estudos evolutivos sobre a carreira docente que não explicam os "desvios de rota" encontrados no desenvo/vimento desse profissional do ensino. Oestudo pretendeu identificar níveis de aquisição da profissionalidade docente, nos âmbitos da prática pedagógica, da autonomia e da identidade profissional, e a investigar formas de reação dos professores a conflitos presentes no cotidiano escolar. Foram entrevistados 19 professores de $5^{a}$ a $8^{a}$ séries, de uma escola estadual de Araraquara, Estado de São Paulo, empregando-se um conjunto de histórias que simulavam situações escolares problemáticas. A análise dos depoimentos possibilitou o estabelecimento de três níveis hierárquicos na aquisição da profissionalidade docente, cada qual se fazendo acompanhar de uma forma de reação compensatória ao conflito. O estudo indica que a mudança da prática profissional do professor depende de sua sensibilização não apenas à própria mudança, mas também aos fatores perturbadores centrais, nem sempre percebidos, do equilibrio atingido. O professor pode perceber o conflito, sem que seja sensível à mudança; e pode sensibilizar-se a mudar, sem que saiba como fazê-lo.
\end{abstract}

FORMAÇÃODEPROFESSORES-CONFLITO_PRÁTICAEDUCATNA_ATITUDEDOPROFESSOR 
TEACHER'SPROFESSIONALISMINA CONSTRUCTMISMAPPROACH. This work challenges, on one hand, cognitivist researches that show misconceptions and exaggerated exaltations of teachers' capacity for reflection and autonomy, and on the other, evolutionary studies on the teaching career that do not explain the "detours" found in the development of this professional teaching. The study aims to identify levels of acquisition of professional teaching in the fields of pedagogical practice, autonomy and professional identity, and to investigate teachers' forms of reacting to conflicts in everyday school life. Nineteen teachers from the $5^{\text {th }}$ to $8^{\text {th }}$ grades from a state school in Araraquara, São Paulo State, were interviewed using a set of stories that simulated problematic school situations. The analysis of testimonies allowed for the establishment of three hierarchical levels in the acquisition of professional teaching, each one being accompanied by a form of compensational reaction to the conflict. The study indicates that changes in teachers' professional practice depends on their awareness not just to change itself but also to central disturbing factors, not always noticed, that affect balance. Teachers can notice the conflict, without being sympathetic to changes, and they can become sympathetic to changes but do not know how to make them.

TEACHEREDUCATION-CONFLICT-EDUCATIONAL PRACTICE-TEACHERATTITUDES

Há cerca de quinze anos, vimos integrando um grupo de pesquisa, na Unesp de Araraquara. Foi justamente a experiência de ter coordenado alguns desses projetos (Chakur, 1990, 1991 e 1993) que nos levou a formular algumas hipóteses acerca do desenvolvimento profissional do professor, que exploramos de maneira mais sistematizada no presente trabalho.

Em algumas ocasiões chegamos a propor uma hierarquia de níveis de construção da profissionalidade docente (Chakur, 1995, 1996). Mas esta era, então, uma proposta que apenas se esboçava, sendo necessária a sua verificação em situações mais controladas. Acreditávamos que uma pesquisa especificamente voltada para a questão do desenvolvimento profissional do professor poderia servir não só para comprovar ou refutar as observações que tínhamos realizado de modo mais ou menos assistemático, como também para acrescentar novos dados aos que já conhecíamos. Mais importante, no entanto, é que a leitura que pretendíamos fazer desses dados, apoiada na perspectiva teórica piagetiana, poderia contribuir para estender o campo dessa teoria - que tem focalizado especialmente a conduta lógico-matemática de crianças e adolescentes - e também para inovar na abordagem do tema profissionalização docente.

Este trabalho partiu, assim, de hipóteses surgidas em projetos realizados com professores de $5^{\mathrm{a}}$ a $8^{\mathrm{a}}$ séries e resume nossa tese de livre-docência, recentemente publicada (Chakur, 200 I). A tese buscou investigar a existência de níveis de cons- 
trução da profissionalidade docente, nas esferas da prática pedagógica, da autonomia e da identidade profissional, bem como caracterizar a atitude do professor diante de conflitos presentes no cotidiano escolar, recorrendo à perspectiva piagetiana. Tentamos, ao mesmo tempo, contrapor esse estudo, de um lado, a investigações da corrente cognitivista que exaltam incondicionalmente as capacidades de reflexão e autonomia do professor e, de outro, a estudos da vertente evolutiva que focalizam perfis vocacionais e o ciclo de vida profissional dos professores, sem que haja explicações sobre os "desvios de rota" encontrados ao longo da carreira docente.

\section{EM BUSCA DE UMA TEORIA DA PROFISSIONALIDADE DOCENTE}

Estudos realizados segundo a abordagem cognitivista (o paradigma do pensamento do professor, no dizer de Imbernón, 1994; Shavelson, Stern, 1981; e Zabalza, 1994), intensificados a partir dos anos 80, têm defendido o ensino como prática reflexiva e valorizado os saberes que o professor adquire na própria atuação (Giovanni, 1994; García, 1992; Nóvoa, 1992, 1994, 1995; Pérez Gómez, 1992; Schön, 1992, 1992a; Zeichner, 1992, 1993). Tais estudos freqüentemente fazem referência a dois modelos básicos de formação e atuação do professor: os modelos da racionalidade técnica e da racionalidade prática.

No primeiro, concebe-se o professor como técnico-especialista e a prática pedagógica como intervenção tecnológica, caso em que o professor deve formarse no domínio dos conteúdos especíícos de que vai tratar (componente científicocultural da formação) e em competências e habilidades de atuação prática (componente psicopedagógico), para que seja capaz de solucionar problemas práticos recorrendo a normas e técnicas derivadas do conhecimento científico.

No modelo da racionalidade prática, são utilizadas expressões tais como prático reflexivo, investigador, profissional clínico para definir a figura do professor. A prática é concebida como processo de investigação na ação, núcleo da formação docente e lugar da produção do saber, enquanto a formação se torna desenvolvimento profissional.

Segundo Pacheco ( 1995), o paradigma de investigação do pensamento do professor inaugurou-se formalmente na Conferência norte-americana de 1974 do National Institute of Education. As primeiras investigações partiram do Institute for Research on Teaching, da Universidade de Michigan, EUA, e eram relacionadas com o processo de tomada de decisão. Essas pesquisas apresentavam uma orientação marcadamente psicológica, elegendo a cognição do professor e suas teorias 
práticas como as principais variáveis que interferem no processo ensino-aprendizagem.

Os estudos realizados a partir de então concentraram-se em duas dimensões (processamento de informação e tomada de decisão), três momentos de atuação (decisões pré-ativas, interativas e pós-ativas) e um contexto psicossocial (constructos, crenças, teorias implícitas, juízos, dilemas).

Em trabalho de revisão das pesquisas que tratam do pensamento do professor, Shavelson e Stern ( 1981 ) fornecem um panorama dos temas e métodos empregados nesses estudos. $\bigcirc$ domínio conceitual dessa abordagem compreende desde estudos que focalizam condições antecedentes como informações sobre os alunos, natureza da tarefa de instrução, ambiente escolar ou de sala de aula; características do professor como crenças, concepções sobre o conteúdo, complexidade cognitiva; seus processos cognitivos (informação, seleção e integração, incluindo atribuições e processos heurísticos e inferências) e até as conseqüências desses processos para o professor (planejar a instrução, estabelecer interação com o aluno), para o aluno e para a avaliação do professor (de julgamentos, decisões e rotinas de ensino).

Shavelson e Stern ( 1981, p.472) apresentam um modelo de julgamento e de tomada de decisão que concebe os professores como agentes ativos que dispõem de muitas técnicas instrucionais. Para fazer escolhas a partir desse repertório, eles devem integrar uma grande quantidade de informações sobre os estudantes, advinda de fontes variadas, que precisa ser de algum modo combinada com suas próprias crenças e metas, com a natureza da tarefa instrucional, com as pressões da situação etc. A informação que é assim selecionada e integrada assenta-se em certas heurísticas e atribuições causais, permitindo ao professor fazer julgamentos sobre os alunos acerca de sua capacidade, esforço e comportamento. São esses julgamentos que guiarão as decisões do professor em sala de aula.

Zabalza (1994) também descreve de modo sistematizado a estrutura conceitual do paradigma do pensamento do professor, com suas dimensões, momentos de atuação e campos do universo cognitivo dos professores, já expostos anteriormente.

Clandinin ( 1985), por sua vez, adjetiva de modo especial o conhecimento prático dos professores. Segundo ele, deve-se falar em conhecimento prático pessoal do professor, que tem sua origem e expressão na ação. $\bigcirc$ termo pessoal significa, nesse caso, que o conhecimento participa e está impregnado de tudo o que uma pessoa é. $\bigcirc$ autor chama a atenção para o "fator local individual que ajuda a constituir o caráter, o passado e o futuro de qualquer indivíduo". Assim, conheci- 
mento prático pessoal é aquele que "está impregnado com todas as experiências que conformam o ser de uma pessoa. Seu significado deriva-se e é compreendido em termos da história de experiência da pessoa, tanto profissional como pessoal" (p.362).

A ênfase no caráter pessoal e idiossincrático dos conhecimentos originados na prática docente e aí aplicados tem levado, inclusive, alguns pesquisadores a tentar atestar essa particularidade tomando a si próprios como sujeitos. Este é o caso de Lampert (1 985), por exemplo, que descreve um estudo de caso tratando de um dilema que ela própria deveria resolver de modo a atender duas crianças que estavam atrasadas no trabalho escolar. Segundo a autora, o que deve distinguir a perspectiva da prática da perspectiva do construtor de teoria é a ênfase do professor sobre particularidades concretas na descrição do problema de uma classe. Assim também, há uma diferença fundamental, embora menos familiar, relativa à qualidade pessoal dos problemas do ensino, na visão de um prático.

Proposições relativamente recentes desses e de outros autores parecem fazer parte de uma nova visão acerca da profissionalidade do professor. Todos concordam em dar à profissão docente uma racionalidade própria, mas nem sempre coincidem as interpretações sobre a natureza, os processos, mecanismos ou produtos da atividade cognitiva dos professores. Zabalza (1994) é um dos autores que chamam a atenção para a variedade de denominações e conceitos empregados nos estudos sobre o pensamento do professor. Fala-se, segundo ele, em construtos pessoais, perspectivas, princípios educativos, concepções, teorias em ação, conhecimentos práticos e epistemologias. Deparamo-nos, também, com termos e expressões tais como saberes docentes, pensamento reflexivo do professor, teorias práticas, teorias implícitas, ou mesmo pensamento prático, nas tentativas de definir, exatamente, "o que se passa na cabeça do professor".

As diferenças e ambigüidades são visíveis quando se trata de definir precisamente o que se concebe como pensamento do professor, reflexão e ensino reflexivo. Pelo que observamos, o conceito mesmo de reflexão não se encontra suficientemente esclarecido. Fala-se, por exemplo, em formas de reflexão - introspecção, exame, indagação e espontaneidade, como propõem Weiss, Louden (apud García, 1992); em níveis de reflexão - técnico, prático e crítico, segundo Zeichner e Liston, ( 1987$) ;$ em dimensões - compreensão das matérias pelo aluno, interação professor-aluno e dimensão burocrática da prática, como propõe Schön (1992); e em momentos da reflexão - reflexão na ação e reflexão sobre a ação e sobre a reflexão na ação, que, juntamente com o conhecimento na ação, integram o pensamento 
prático do professor, segundo Schön (1992 e 1992a). Zeichner (1993) reforça a crítica, atribuindo, inclusive, a "ilusão da reflexão" a certas concepções do professor como prático reflexivo, que subvertem a intenção de emancipá-lo, ao mantê-lo em posição submissa.

A nosso ver, a caracterização do professor como prático reflexivo situa-se em um nível superior do desenvolvimento da profissionalidade e, para que essa caracterização se sustente teoricamente, torna-se fundamental a tarefa de definir com maior precisão os conceitos de reflexão e prática reflexiva. Consideramos bastante promissor, como caminho para aí chegar, rever certas proposições piagetianas, que comentaremos adiante.

Outra vertente de trabalhos, que podemos chamar evolutiva, focaliza fases da vida profissional dos professores. Huberman ( 1995), por exemplo, trata do ciclo de vida dos professores, apontando suas tendências gerais. Considera que a carreira docente comporta certa seqüência e propõe um esquema com fases e temas ordenados de acordo com o tempo de carreira. Assim, os primeiros três anos correspondem à entrada e tateamento; de 4 a 6 anos, há a estabilização, consolidação de um repertório pedagógico; entre 7 e 25 anos, ocorre diversificação, ativismo ou questionamento; entre 25 e 35 anos, aparecem a serenidade, distanciamento afetivo ou conservantismo; e entre 35 e 40 anos, temos o desinvestimento (sereno ou amargo). Segundo Huberman, a carreira docente pode tomar diferentes percursos, sendo o "mais harmonioso" o que se conforma à seqüência diversificação $\rightarrow$ serenidade $\rightarrow$ desinvestimento sereno. Mas há percursos problemáticos, como: questionamento $\rightarrow$ desinvestimento amargo; questionamento $\rightarrow$ conservantismo $\rightarrow$ desinvestimento amargo.

Outro estudo nessa linha foi realizado por Cavaco (1995), que pesquisou a trajetória de vida pessoal e profissional de vários professores portugueses, de diferentes idades e tempos de exercício no magistério secundário.

Segundo a autora, os primeiros anos de magistério são de instabilidade, insegurança e sobrevivência, "mas também de aceitação dos desafios, da criação de novas relações profissionais e da redefinição das de amizade e de amor" (Cavaco, 1995, p. 179). Numa segunda fase (em torno dos 30 anos de idade), o professor volta-se mais às tarefas pedagógicas e sente-se mais seguro diante da estabilidade conseguida no emprego e da permanência numa mesma escola. Entretanto, na tentativa de ocupar plenamente o seu espaço de trabalho, o professor pode caminhar por duas vias divergentes, dependendo da presença ou ausência e condições favoráveis: diversificar e enriquecer seu trabalho e sua própria formação ou, ao 
contrário, cristalizá-los em rotinas repetitivas e automatizadas, às vezes priorizando atividades que complementam o salário e caracterizam o que, no Brasil, chamamos de "bicos". Entre os 35 e 40 anos, inicia-se a fase em que o professor tende a "refletir com realismo o mundo do trabalho, articulando-o com o universo familiar e referindo a sua experiência de vida com desalento e ceticismo" (Cavaco, 1995, p. I 82). Dois caminhos são, novamente, possíveis: o estabelecimento de uma rotina de trabalho e o envolvimento do professor com a dimensão burocrática; ou, ao invés disso, a aceitação das inquietações como desafios, que conduz o professor à busca de alternativas mediante um processo de revalorização pessoal e de aquisição de autonomia (p. I 83). Uma quarta etapa, enfim, mostra-se "confusa e contraditória", tendo em vista a aposentadoria iminente. Podem surgir, de um lado, a procura de novas ocupações e a retomada de antigos projetos que se contrapõem à rotinização e ao conformismo. Mas o professor pode caminhar em sentido oposto - do isolamento e fechamento em um quadro profissional restrito -, o que o conduz à resignação amarga, ao fatalismo, à descrença nos valores positivos da mudança (p. 187).

De modo semelhante a Huberman, Cavaco salienta que a possibilidade de apontar traços seqüenciais, perfis de desenvolvimento vocacional, não se atrela à "existência de indicadores normativos que regulem a direção, o ritmo, as finalidades e as modalidades do processo de evolução profissional” (Cavaco, 1995, p. 179). Nesse sentido, podemos afirmar que tais estudos não apontam para níveis propriamente evolutivos de formação docente - os níveis de construção da profissionalidade docente, que buscávamos com esta pesquisa. Quando muito, trata-se de descrever etapas da história de vida profissional dos professores, seqüenciando-as conforme o critério do simples desenrolar dos fatos em ordem cronológica, que pouco lembra a noção psicogenética de nível de desenvolvimento.

Não podemos negar que o desenvolvimento profissional esteja intimamente relacionado com o desenvolvimento pessoal, como propõem Cavaco (1995), Huberman (1995) e Nóvoa (1992). Mas questionamos - inclusive porque ainda faltam investigações a respeito - a ausência de um mecanismo regulador responsável pelo controle dos desvios de rota, que podem ser constatados em cada uma das etapas descritas por Cavaco e Huberman, por exemplo. Tal como enunciam os autores, o desenvolvimento profissional docente poderia, em cada caso, tomar rumos divergentes, sem qualquer explicação racional, pois nada indica que os professores pesquisados tenham sido submetidos a condições e circunstâncias opostas. Por essa razão, acreditamos que uma leitura piagetiana desse desenvol- 
vimento daria maior coerência e consistência às interpretações dos desvios encontrados.

\section{CONSTRUTIVISMO PIAGETIANO E PROFISSIONALISMO DOCENTE}

Identificamos pelo menos três construções teóricas de Piaget que podem fundamentar o estudo da profissionalidade docente. São elas: a teoria da equilibração das estruturas cognitivas, na qual são particularmente relevantes as noções de abstração reflexiva, níveis de desenvolvimento e formas de reação compensatória a elementos perturbadores; a teoria da tomada de consciência, em que se salientam as diferenças entre o fazer e o compreender, com seus mecanismos de regulação; e a teoria do desenvolvimento do juízo moral.

Em obra clássica que descreve o processo de equilibração das estruturas de conhecimento, Piaget ( 1975) parte do postulado de que assimilação e acomodação constituem os componentes de todo equilíbrio cognitivo, responsáveis, portanto, pela conservação do sistema cognitivo.

Para desenvolver-se, um esquema (ou estrutura) deve ser ativado; um esquema tem necessidade de "alimentos" para que funcione. Em situações de intercâmbio com o meio, na medida em que o esquema de assimilação é posto em funcionamento, o sujeito fatalmente se depara com novos objetos e situações que oferecem obstáculos à assimilação e provocam desajustes no esquema em atividade. São desajustes que necessitam ser compensados para que haja reequilíbrio. Ocorre que o reequilíbrio tem sempre um elemento de novidade, ou se produz em novas bases (reequilíbrio localizado ou reequilibrações estruturais de conjunto): o esquema pode, assim, diferenciar-se para melhor ajustar-se à situação (acomodação), ou se combinar com outros (assimilação recíproca) para dar conta do objeto ou situação inicialmente inassimilável.

Para que as perturbações interpostas pela realidade ao equilíbrio alcançado possam ser integradas à estrutura cognitiva, o sujeito recorre a certas reações compensatórias, formas de reagir ao elemento perturbador de modo que compense seus efeitos e reaver o equilíbrio perdido. Piaget (1975) propõe três formas de compensação, sendo a primeira a mais elementar e a última, a mais avançada.

Assim, diante de uma situação desestabilizante, uma das reações do sujeito pode ser a de simplesmente tentar anulá-la, modificando a ação original em sentido inverso daquele da perturbação. Se a perturbação for sentida de modo mais intenso, o sujeito pode reagir negando o fator perturbador, negligenciando-o ou afastando-o. Essas são condutas chamadas por Piaget de tipo $\alpha$. Particularmente no segun- 
do caso, não existe propriamente conflito aos olhos do sujeito, que acrescenta elementos que deformam de algum modo a situação para assimilá-la ao que é "normal", familiar, comum.

$\mathrm{Na}$ conduta de tipo $\beta$, há tentativas de integração do elemento perturbador ao sistema, que se modifica por deslocamento de equilíbrio. Diante do problema ou obstáculo à assimilação, o sujeito não mais tentará anular o elemento perturbador, mas buscará modificar o esquema disponível, de modo a ajustá-lo à situação em desequilíbrio. Assim, "o que era perturbador, torna-se variação no interior de uma estrutura reorganizada, graças às relações novas que unem o elemento incorporado àqueles que já estavam organizados" (Piaget, 1975, p.72).

$\mathrm{Na}$ conduta de tipo $\gamma$, por fim, o fator perturbador integra-se ao sistema cognitivo, quando, então, podem ser antecipadas todas as variações possíveis, "as quais perdem, enquanto previsíveis e dedutíveis, seu caráter de perturbações e se vêm inserir nas transformações virtuais do sistema" (Piaget, 1975, p.73).

A equilibração, como diz Piaget (1975, p.36-37), não se constitui, portanto, em simples marcha para o equilíbrio, sendo, além disso, "uma estruturação orientada para um melhor equilíbrio, sendo que nenhuma estrutura equilibrada permanece em estado definitivo, mesmo quando conserva na seguinte seus caracteres especiais sem modificações".

Deve ser lembrado, por outro lado, que toda atividade humana, segundo Piaget ( 1977), exige algum grau de consciência, que se pode revelar elementar ou periférica na medida em que se aplica a dados imediatamente percebidos, aos objetivos da ação ou aos seus resultados constatados como êxito ou fracasso. Mas a consciência pode chegar à compreensão (aos meios utilizados, à razão das coisas) com o recurso à tomada de consciência.

Desse modo, para Piaget, a tomada de consciência procede da periferia da ação aos seus mecanismos centrais, ou seja, dos objetivos e resultados percebidos como sucesso ou fracasso aos meios utilizados e às razões que produziram determinado resultado. A busca de um objetivo estaria no ponto de partida, com a constatação consciente do êxito ou fracasso daí resultante. No caso de fracasso, o sujeito trata de explicar por que ocorreu. Partindo do dado de observação relativo ao objeto (resultado falho, fracasso), o sujeito procurará saber por que houve falha de adaptação do esquema ao objeto; e partindo do dado de observação relativo à ação (objetivo, direção), ele focalizará sua atenção nos meios empregados e em suas correções ou substituições.

Vale lembrar, contudo, que a conscientização não é uma espécie de iluminação. Não é algo que ocorre mecanicamente, tampouco de modo imediato. Piaget 
(1977) refere-se, inclusive, a graus de consciência, o que significa dizer graus de reflexão.

Piaget também trata da questão da autonomia em seu aspecto evolutivo. Em sua obra sobre o desenvolvimento do juízo moral (Piaget, 1994), apresenta estudo sobre a prática e a consciência da regra, no contexto do jogo coletivo. Sua análise das condutas infantis revela que a criança situa-se, inicialmente, numa fase de anomia, quando não é capaz de seguir regras coletivas e nem mesmo se interessa por elas. Numa segunda etapa, da heteronomia, a criança já demonstra interesse em participar de um jogo em que as regras normatizam as condutas, mas concebendo-as como algo imutável e sagrado, e não como um contrato convencionalmente firmado entre os jogadores. Por fim, na etapa da autonomia, a criança joga segundo as regras eleitas pelo grupo, concebendo-as como fruto de acordos mútuos entre os jogadores, cada qual podendo agir como "legislador", desde que se submetendo à apreciação e decisão coletivas.

Evidentemente, no âmbito da profissionalidade docente, a questão da autonomia envolve algo mais que a submissão ou o respeito a regras, já que se trata da esfera do trabalho adulto. Abordando a questão da autonomia docente, Cattani esclarece, por exemplo, que, além do nível individual, a autonomia expressa-se em outros dois níveis, de domínio do coletivo:

No primeiro corresponde às atividades laborais e implica a possibilidade de escoIha das tarefas, dos meios e do sentido do trabalho, resultando em dignidade e satisfação. $O$ segundo remete à ação política generalizada, à vida em sociedade e à produção cultural. Ter autonomia nessas esferas significa viver em sociedade, mas livre de imposições tirânicas, de normas arbitrárias, de trabalhos servis [...] exige árduos esforços, aumento de responsabilidade e engajamento permanente. (1996, p. 147)

Cattani considera, também, que a autonomia se faz acompanhar de um processo de autovalorização que passa, por sua vez, pela competência resultante da formação profissional.

Segundo pensamos, são inerentes ao conceito de autonomia profissional a iniciativa ou capacidade de tomar decisões refletidas, quando a situação assim o exige, e a liberdade de ação, mas com dois condicionantes, já sugeridos por Cattani: que a ação seja responsável e que se subordine à razão coletiva (o engajamento de que fala o autor).

Tendo em vista as considerações acima, levantamos alguns problemas que consideramos especialmente relevantes e que tentamos abordar numa pesquisa 
focalizando a profissionalidade docente: poderiam ser identificadas e delimitadas fases no desenvolvimento dessa profissionalidade. Em caso positivo, quais as suas características evolutivas? Como se apresentariam a prática pedagógica, a autonomia e a identidade profissional docente em sua forma mais aperfeiçoada e elaborada? $\bigcirc$ que pode revelar-se como fator perturbador à profissionalidade docente, no cotidiano escolar, e como esse fator tende a ser compensado pelo professor?

Segundo pensamos, a investigação desses problemas e de outros afins poderá contribuir para uma aproximação fecunda entre o construtivismo piagetiano e a teoria do desenvolvimento profissional docente, ainda em fase de elaboração.

\section{OBJETIVOS DA PESQUISA}

A perspectiva piagetiana define o desenvolvimento cognitivo como um processo de construção de formas cada vez mais equilibradas, constituindo-se num duplo processo de descentração: o eu individual descentra-se, progressivamente, em relação a outras perspectivas, chegando à autonomia e às relações de reciprocidade e cooperação; ao mesmo tempo, a coordenação (de aspectos, partes, dimensões das coisas) substitui a centração inicial em particularidades do objeto, aproximando-se cada vez mais da objetividade.

Segundo Piaget, o processo de desenvolvimento dos conhecimentos toma a forma de uma seqüência de períodos, com suas subdivisões em estádios que se sucedem em ordem fixa e irreversível. A passagem de uma a outra etapa submete-se, então, ao processo de equilibração, em que o sujeito opõe reações compensatórias (regulações) às perturbações que o meio oferece (sofridas ou antecipadas).

Partindo dos pressupostos acima, este trabalho pretendeu transportar a leitura piagetiana do desenvolvimento cognitivo para o estudo da profissionalidade docente. Eram seus objetivos: identificar possíveis níveis evolutivos no âmbito dessa profissionalidade, tomando para estudo a prática pedagógica, a autonomia e a identidade profissional; investigar maneiras pelas quais o professor concebe e resolve problemas e conflitos encontrados no cotidiano escolar.

\section{METODOLOGIA}

Como sujeitos da pesquisa, foram tomados 19 professores de variadas disciplinas de $5^{\mathrm{a}}$ a $8^{\mathrm{a}}$ séries, lecionando em escola pública de um bairro periférico da 
cidade de Araraquara, São Paulo. As idades variavam de 23 a 47 anos, e o tempo de serviço, de três a 20 anos'.

O instrumento de investigação era composto por oito histórias simulando situações do cotidiano escolar, cada qual contendo um problema ou conflito que um professor, como personagem principal da história, deveria julgar e/ou solucionar.

A primeira história, sobre indisciplina, focalizava a prática pedagógica e contava que um professor deveria tomar uma atitude diante de um aluno de $5^{a}$ série que, segundo ele, fazia "muita bagunça". Pedíamos uma avaliação do comportamento do aluno para perguntar que atitude o professor hipotético teria tomado na ocasião perguntas que se repetiam para o caso de alunos de $8^{a}$ série.

A história sobre rendimento escolar também centrava-se na prática pedagógica e contava que $50 \%$ de alunos de uma classe apresentaram baixo rendimento na disciplina do entrevistado, em avaliação feita no início do ano. $\bigcirc$ entrevistado deveria explicar o fracasso dos alunos, sugerir como o professor do relato deveria agir com os "alunos fracos" e o que deveria fazer com a matéria que havia sido programada para a classe e com o livro didático selecionado. E novamente perguntávamos o que deveria fazer o professor se, após as medidas tomadas, dez alunos permanecessem sem acompanhar a matéria.

A terceira história era sobre motivação, também focalizando a prática pedagógica. Abordava o problema de um professor com três alunos de uma classe de $8^{a}$ série, que eram muito unidos e não conseguiam prestar atenção nas aulas da disciplina do entrevistado. Solicitávamos que o entrevistado imaginasse o motivo da falta de atenção dos alunos e sugerisse soluções para o problema - questões que eram repetidas para o caso de alunos do período noturno.

A história sobre merenda destinava-se a avaliar a identidade profissional do professor. Contava que uma escola tinha merenda irregular e um professor tentava suprir a falta de merenda trazendo lanche de casa para seus alunos. Perguntávamos como o entrevistado explicaria a situação da escola e dos alunos, se o professor agia bem trazendo o lanche e o que mais poderia fazer. E supondo que não mais a merenda faltasse, mas a merendeira, perguntava-se o que o professor da história poderia fazer, e se ele iria fazer a merenda.

I Os professores eram, na época da pesquisa, participantes de um projeto de parceria com universidade e escola do ensino fundamental (financiado pela Fapesp e pelo CNPq), ao qual se integrava também a autora deste artigo, e quatorze desses docentes que acompanharam os quatro anos de duração do projeto. 
A história sobre rotina pedagógica voltava-se, novamente, para a prática pedagógica. Tratava de um professor que dava aulas sempre da mesma maneira (descrevíamos uma aula nos moldes do ensino verbalista tradicional) e que se saía bem nas classes de $7^{\mathrm{a}}$ série, mas teve problemas ao aplicar o procedimento à classe de $5^{\mathrm{a}}$ série (alunos com condutas inadequadas, incompreensão da matéria). Pedíamos explicações sobre as condutas dos alunos, o procedimento (por que não deu certo) e a decisão do professor (por que agiu do mesmo modo em classes diferentes), além de sugestões para eliminar as condutas inadequadas dos alunos e fazê-los compreender a matéria.

Na história sobre conflito professor-alunos, em que pretendíamos avaliar a autonomia profissional, contávamos que um professor experiente e bem preparado recebeu recusa de uma turma de $8^{a}$ série, bastante questionadora e ativa, quando decidiu fazer chamada oral para nota, após fazer revisão da matéria. Solicitávamos explicação das condutas dos alunos e do professor hipotético e julgamento de quem tinha razão na história, além de sugestões de solução para o impasse.

A situação de conflito entre colegas focalizava a identidade profissional. Contava que dois professores cobravam-se mutuamente porque um aluno de $7^{\text {a }}$ série, bom (na disciplina do entrevistado), fracassava quando a tarefa envolvia também conteúdo de outra disciplina (a do colega). Pedíamos explicações sobre o problema do aluno e julgamento sobre qual dos professores tinha razão em "cobrar" do outro a responsabilidade ou solução do problema, e quem teria razão, se um dos professores (ora um, ora outro) fosse substituto temporário. No final, pedíamos sugestões para a solução do impasse.

A última história, sobre conflito professor-diretor, pretendia avaliar a autonomia docente. Abordava o caso de um professor que sofre proibição do diretor porque oferecia atividades diferentes, que geravam barulho na classe, embora fossem produtivas. Pedíamos explicações sobre a conduta dos alunos (por que ficavam agitados) e do professor (insistência em dar aquelas atividades e não outras) e perguntávamos quem teria razão (professor ou diretor). Essa questão era repetida para o caso de um colega (ou de vários) reclamar e solicitávamos, ao final, soluções possíveis para o impasse.

Vale lembrar que, em algumas histórias, solicitava-se que o entrevistado imaginasse a decisão que o personagem-professor deveria tomar a respeito do problema; em outras, pedíamos que apenas julgasse a atitude do personagem. Mas, em todas elas, havia questões que solicitavam explicações acerca de condutas dos personagens e soluções possíveis para o problema ou conflito. Também em todas as 
histórias, dava-se início ao interrogatório solicitando uma avaliação geral da situação apresentada.

O instrumento foi aplicado individualmente, a cada professor da amostra, numa mesma ordem. Para tanto, empregamos a entrevista informal (clínica), seguindo o método de exploração crítica piagetiano (Domahidy-Dami, Leite, 1987; Piaget, s/d).

Para avaliar os dados, empregamos, inicialmente, a análise qualitativa dos depoimentos, um por um, e estabelecemos certas categorias, agrupando depoimentos semelhantes segundo critérios empíricos combinados com outros de caráter teórico, sugeridos em obras piagetianas (por exemplo, Furth, 1980; Piaget, 1975). Em seguida, buscamos seqüenciar tais categorias em níveis distintos.

A análise privilegiou critérios tais como centração versus descentração (com relação a personagens, aspectos de comportamento, resultado constatado), aparência/imediatismo versus não-aparência/não imediatismo (de traços ou características levantadas), grau de flexibilidade da prática, grau de autonomia/ responsabilidade quanto à própria ação, grau de assimilação da função docente e grau de responsabilidade profissional, além de qualidade argumentativa dos depoimentos. $\mathrm{Na}$ análise das sugestões sobre atitudes dos professores diante dos conflitos, tomamos como critério as três formas de reações compensatórias propostas por Piaget (1975) e comentadas atrás.

\section{RESULTADOS}

Os resultados indicam que a profissionalidade docente, tomada em seus três eixos - prática pedagógica, autonomia e identidade profissional -, desenvolve-se em níveis distintos de equilíbrio, que denominamos níveis de construção da profissionalidade docente. São níveis dispostos hierarquicamente, em ordem de crescente aperfeiçoamento. Observamos, igualmente, que as reações dos professores a situações de conflito são bastante semelhantes às formas compensatórias de desequilíbrios propostas por Piaget.

Os três níveis encontrados estão caracterizados em seguida. Alguns exemplos de depoimentos dos professores, transcritos literalmente, acompanham cada nível para ilustrar certas características. Ao final de cada exemplo, constam, entre parênteses, o nome fictício do professor, sua idade e tempo de serviço.

Nível I. Profissionalidade fragmentada, com desvio de identidade: que apresenta como traços básicos a prática reiterativa automatizada, a heteronomia e o desvio de identidade. 
A prática pedagógica toma a forma de rotinas cristalizadas, que se parecem reproduzir por força da centração em aspectos aparentes do comportamento do aluno (geralmente de caráter negativo) e em objetivos e resultados da ação do professor (conseguir). É uma prática que revela automatismo à medida que resiste à mudança e que são aplicados os mesmos esquemas de atuação (geralmente característicos de práticas tradicionais de ensino) a situações, classes de alunos e contextos diferentes.

As soluções para lidar com problemas relacionados à gestão de classe (condutas tidas como inadequadas, por exemplo) são predominantemente heterônomas, repressivas e descomprometidas com a aprendizagem do aluno: o professor pode lançar mão, simplesmente, de medidas repressivas, ou delegar a outrem sua função de gestor da classe, omitindo-se da responsabilidade que lhe é própria como agente educativo. Exemplos:

(Rotina) (Como avalia a situação?) Pra começar, tem que fazer: "Gente, vamos esclarecer, não estamos nos entendendo!" Eu começo tudo de novo. Eu escrevo toda a instrução na lousa passo por passo, desenho e falo: "Vocês vão ter que fazer diferente, mas parecido com esse"!. Não dá pra ela dar visto numa classe dessas. Vai demorar um bom tempo até todo mundo acostumar com esse ritmo. (Ada, 30; 4)

(Indisciplina) (Como avalia a situação?) "Você não vai tirar a bunda da carteira sem minha permissão. Não vai emprestar mais nada enquanto não fizer a atividade'. (Resolve?) Muitas vezes resolve, outras vezes não resolve, então é pegar esse aluno e levar pra direção, último caso (...) eu mudo de posição o aluno, ele já fica meio quieto - senta isolado, sozinho, quando tem espaço pra fazer isso. ( $O$ que você diria desse aluno?) Está com graça, quer chamar a atenção ou tem falta mesmo de atenção, ou não se interessa por nada, ele está ali pra brincar, sem vontade de fazer nada. (Ada, 30; 4)

Quando o problema relaciona-se com a gestão da matéria ou do conteúdo, o professor recorre, com maior freqüência, a medidas reiterativas/remediadoras (repetir, reforçar o conteúdo), mas também a soluções heterônomas que o isentam da responsabilidade pelo fracasso constatado. A heteronomia, na verdade, é uma atitude generalizada, mostrando-se na submissão aos constrangimentos da situação e às pressões da hierarquia. Exemplos:

(Rendimento) (O que a professora deveria fazer com os alunos "fracos"?) Eu volto com a matéria, mas os alunos fracos eu vou chamar a atenção (... - - "Capricha mais, se esforça mais (...)!" Dou mais atenção. É um pouco de falta de capricho, também, de seguir a matéria, a ordem, a disciplina no caderno. (E se ainda assim, pelo menos 
10 alunos continuassem sem aprender a matéria?) $\bigcirc$ negócio ia ficar feio, ia ferver (...) Eu ia continuar prosseguindo a matéria e ia tocar o barco. (A professora precisaria de alguma ajuda?) Você explica, explica... aí não sei o que ia fazer, só se for com médico, psicólogo, farmacêutico, com mãe. Se eu mudando tudo e não aprende ainda, está sendo retardado, um atraso. (Ada, 30; 4)

(Conflito professor-diretor) (Avaliação geral) Eu chegaria para os meus alunos e falaria: "Olha, gente, a gente vai ter que se comportar, a diretora já veio aqui e cortou a nossa atividade. Ou a gente manera, fala baixinho, ou vai ficar nessa". (Por que a professora insistia nessas atividades?) Porque está rendendo. Pode ter um pouco de indisciplina, mas se o faturamento é 80\%! (!) Agora, quando não produz nada e é bagunça (...) tem até razão a diretora chegar e implicar. (Ada, 30; 4)

A identidade mostra-se fragmentada e suas fronteiras são quase indefinidas. A fragmentação e confusão da identidade profissional revelam-se, por exemplo, na aceitação ou conivência com desvios de função, no baixo grau de consciência do papel profissional e na negação ou omissão de responsabilidade - seja pelo próprio desempenho conseguido, seja por problemas de comportamento manifesto, ou de aprendizagem, apresentados pelos alunos.

Nesse nível, a profissionalidade docente não revela espírito de corpo. Parece inexistir, do ponto de vista do professor, a necessidade de partilhar conhecimentos, procedimentos, valores e normas reguladoras da profissão docente. Os depoimentos sugerem que "alguns são mais professores do que outros", reafirmando a hierarquia profissional instituída nas várias esferas ligadas ao ensino. Exemplos:

(Merenda) (Avaliação geral da situação) Ah! É triste! Eu acho que o aluno fica irritado na sala de aula. Qualquer coisinha que você vai falar - "Gente, vamo ficar quietos!" é só você falar que algazarra mais ainda, aí que piora a situação. Isso de levar lanche eu acho que é legal, bacana, ou fazer que limpe, ou fazer lanche comunitário - todo mundo traz um lanchinho a mais de casa se tem condição, e fazer lanche comunitário com eles. Agora, que crianças com fome ninguém segura... (Ada, 30; 4)

(Conflito entre colegas) (Avaliação geral) Já tive casos assim. Letras horrorosas, letras, assim, ilegíveis, de falar: "Senta aqui e lê para mim o que você escreveu, que eu não consigo" (...) Mas eu ir em cima e falar para o professor que o outro escreveu errado, não vou mesmo, eu não faço. Agora, nesse caso aí, de ela ter ido falar, ela foi uma besta, eu acho. Porque a outra vai ignorar tudo, ela nunca vai falar que o aluno dela está mal naquela matéria, é uma coisa lógica. Eu sei que tem aluno meu que não sabe [fazer] nada, não sabe e acabou! Eu vou assumir isso, que ele não sabe. Já peguei na mão dele, já fiz de tudo, ele não sabe. Agora, se não sabe Português [disciplina da colega], acentuação, um monte de coisa, troca as letras, eu vou falar para ela, eu vou arrumar encrenca, eu vou arrumar uma inimizade. (Ada, 30; 4) 
As reações aos conflitos tomam a forma de negações ou afastamentos, às vezes deformando elementos da situação para tentar assegurar a harmonia. Notase que o professor tende a ceder à pressão exterior ou a insistir no confronto com base na "razão da autoridade" e, assim, não percebe o conflito. Tais reações, bem como as tentativas de solução, neste nível, são fundadas no dever heterônomo (Piaget, 1994) e se apóiam em esquemas mentais familiares (Boder, 1996; Inhelder, De Caprona, 1996), que "traduzem" a situação para o professor e determinam o que ele consegue realmente perceber numa situação de conflito. Exemplos:

(Conflito professor-alunos) (Como resolver o impasse?) Tem que ser chamada oral? Dou um trabalho pra fazer, atividade em grupo (...) Tem que chamar a direção. Chamaria o pai, a mãe no outro dia (...) Os pais iam dar razão pra mim! Outros iam puxar o saco dos filhos. (Ada, 30; 4)

(Conflito entre colegas) (Quem teria razão em cobrar...?) A professora de Matemática (a colega) que não tem razão. Vou pedir o caderno pra ver, a caderneta, as provas dele, eu vou pedir e falar (para a colega): - "Vamos fazer um teste, vou fazer continha e na tua frente eu vou mandar o aluno fazer, aí a gente tira a dúvida" (...) Agora, se ele tira A em todas as partes de Matemática, vai ser problema do professor de Matemática (...) (E se a professora de... fosse uma substituta temporária, quem teria razão?) A professora de Matemática ainda estaria errada. Já que (a professora de...) estava substituindo mesmo, por que vai atrás disso? Deixa quieto. Já que ela é a substituta, por que agora vai ter que correr atrás disso? Não interessa que fique por pouco tempo, a outra (a colega) que se vire. Joga a batata quente na mão do outro. (E se a de Matemática é que fosse substituta?) Nossa! Não ia dar nem pra discutir, pelo amor de Deus! Porque acima de tudo é nova aqui, não está sabendo de nada, não pode resolver nada, quem tem que resolver isso é o professor mesmo, que está há mais tempo com o aluno, é o que está por dentro do aluno. (Ada, 30; 4)

Neste nível, enfim, a consciência do professor mostra-se elementar ou periférica, guiada por regulagens automáticas, e a abstração reflexiva opera em termos de simples representação da situação problemática, com ausência de ligações ou com ligações que se mostram apenas parciais, ou mecânicas, entre os observáveis constatados. Com esse grau de consciência, torna-se difícil ao professor compreender a própria prática, o potencial dos alunos e a relação pedagógica que com eles mantém, bem como as relações com colegas e com outros agentes escolares e as próprias funções que lhe cabem como profissional do ensino. 
Nível II. Profissionalidade localizada, com semi-identidade: apresenta como traços principais a mobilidade pontual da prática, a semi-autonomia e a semi-identidade profissional.

A prática pedagógica mostra agora certa flexibilidade sendo, às vezes, demasiadamente flexível e anunciando uma busca cega de alternativas às práticas tradicionais. É uma prática que se apóia em centrações alternadas em diferentes elementos do contexto e em análises das situações problemáticas - análises pontuais ou muito genéricas -, o que resulta em ambigüidades nos julgamentos e nas decisões. É freqüente, também, nos depoimentos desse nível, a busca de razões da dificuldade ou problema levantado, o que mostra que os esquemas interpretativos da situação não estão muito cristalizados. Exemplos:

(Rotina) (Por que o procedimento não deu certo com a $5^{a}$ ?) Matéria de $5^{a}$ é uma revisão da de $4^{a}$. Será que ela domina bem a matéria de $5^{a}$ ? Será que o erro não está nela, que não domina a matéria de $5^{5}$ ? Ou porque os alunos estavam acostumados com aquela professora de $\mathrm{I}^{\mathrm{a}} \mathrm{a} 4^{\mathrm{a}}$, sempre a mesma, que falava a mesma linguagem, e de repente mudou? (Por que a professora agiu do mesmo modo...?) Falta de experiência. Falta tudo. (Não agiu bem) porque uma classe de $7^{\mathrm{a}}$ é uma classe de $7^{\mathrm{a}}$, é uma realidade. Será que nunca ouviu falar que uma $5^{\mathrm{a}}$ a gente deve receber, tem que mostrar, tem que adaptar? Então, falta tudo. (Hilda, 4I; 17)

(Rendimento) (O que a professora deveria fazer com a matéria programada?) Deixaria o plano de curso dela de lado e atenderia à necessidade do aluno (...) (E com o livro adotado?) Usa poesia, jornal [em vez do livro] - vão pesquisar e falar sobre o que mais gosta, tipo seminário, trabalho de quatro. Vamos fazer joguinhos - de dominó com as palavras, com as sílabas. Eles vão criar, eles vão bolar, fazer uma dramatização, brincar de mímica, mas dentro da matéria. (Hilda, 4I; 17)

No que tange à gestão da classe, ainda se notam medidas repressivas, juntamente com outras não repressivas (como conversar com o aluno); na gestão da matéria, predominam soluções acomodadoras, ou seja, medidas que introduzem novos elementos na ação docente para acomodá-la à situação, mas sem implicar mudanças significativas (por exemplo, adequação da linguagem, ou do conteúdo, à capacidade do aluno, dar mais atenção aos alunos que vão mal etc.). Principalmente em depoimentos mais elaborados, ao lado das medidas reiterativas/remediadoras, que continuam, vemos aparecer duas categorias de soluções que parecem bem típicas desse nível e que sinalizam certo grau de reflexão sobre a prática: as medidas investigativas e as soluções de compromisso. Ao invés da simples submissão e conformismo com a situação e das centrações que ocorrem no nível I, o professor 
lança-se à busca de informações, de razões e fatores não imediatamente aparentes que possam dar conta do problema. Nas soluções de compromisso, abala-se o esquema interpretativo familiar de que o professor dispõe e que deve ser modificado para que possa ajustar-se à situação. Exemplos:

(Rotina) (Quanto à incompreensão dos alunos) Ela precisa procurar saber qual o nível da $5^{a}$ série. Se ela for falar num mesmo nível... se adequar a um nível de $5^{a}$ série (...) Quando você me fala "pôr o ponto na lousa", isso me lembra História. Hoje, a gente tem outras formas de diversificar, tem que começar mais de leve na $5^{a}$ série. Acho que, em primeiro lugar, ela tem que explicar muito bem, bem esmiuçadinho mesmo; $5^{a}$ série tem que ser bem detalhista. (Dalva, 33; 9)

(Conflito professor-diretor) (Avaliação geral) Será que o diretor tem autoridade para proibir? Eu primeiro ia procurar saber se ele tem autoridade pra proibir. Porque se eu estou trabalhando, está dando resultado, que é o que importa, eu ia procurar saber (...) Poderia, por exemplo, buscar um espaço alternativo dentro da escola, estou atrapalhando o outro colega, que também precisa de silêncio. (Por que ela insistia em dar as atividades?) Porque ela estava vendo resultado. Mas se fosse eu, me incomodaria atrapalhar outro colega do lado. (Marlene, 33; 7)

Embora consistindo forma incompleta de compensação do elemento perturbador, os compromissos sinalizam, assim, certo grau de integração e, portanto, um início de tomada de conhecimento (compreensão de dados observáveis) e de consciência (compreensão de meios e razões que determinam o "conseguir" e o fracasso). Os esquemas disponíveis começam, então, a descristalizar-se (Boder, 1996) em razão da introdução de regulagens ativas.

O início de descentração torna-se especialmente significativo quando se trata de conflitos que envolvem relações interpessoais. Nesse caso, o conflito como tal já é considerado, mas às custas de centrações alternadas em elementos ou fatores distintos. $\bigcirc$ professor busca, então, justificar, às vezes de modo forçado e rudimentar, as ações e atitudes de um e de outro dos protagonistas envolvidos no conflito. Exemplo:

(Conflito professor-alunos: quem tem razão?) Quem tem razão seriam os alunos de não fazer (a prova). Não acho certo você levar seus problemas pra sala de aula, nem eu ter que agüentar problema do aluno. (Contra-sugestão) Fazendo a revisão... tinha direito de pedir, sim. Eu acho viável o professor pedir, vai analisar se o aluno aprendeu mesmo, ou se está querendo tumultuar. Se revisou tudo, ela tem toda razão de fazer uma avaliação. Mas na medida em que ele está questionando, ele já está devolvendo o que aprendeu, não tem necessidade de fazer uma chamada oral. (Então, os dois têm razão?) Dependendo do ângulo que você vê... (Mônica, 42; I4) 
A autonomia nascente revela-se, por um lado, em atitudes de respeito aos direitos dos alunos, nas situações em que o professor poderia, simplesmente, exercer sua autoridade de modo arbitrário (quando utiliza instrumentos pedagógicos com fins punitivos, por exemplo); e, por outro, na afirmação de respeito aos colegas (na verdade, de receio de incomodá-los), ou de respeito ao diretor, se a classe manifesta-se barulhenta, como fica claro no depoimento de Marlene, apresentado mais acima: "Mas se fosse eu, me incomodaria atrapalhar outro colega do lado".

Por sua vez, os traços de fragmentação/confusão de identidade profissional tornam-se enfraquecidos. O professor já questiona os desvios de função, cuja ocorrência ele próprio condiciona a situações extremadas. Mas algumas soluções mostram um "eu profissional" ainda fragmentado, pois revelam compromissos (compensações parciais) que evitam definições precisas da identidade profissional docente. Exemplo:

(Merenda) (Supondo que a merendeira é que era irregular...?) Poderia, com os alunos, fazer alguma atividade, deixar alguma atividade na classe ou ali próximo a ela e ir fazer a merenda. (Se fosse na escola onde trabalha), tem oito classes, cada dia uma ia fazer a merenda (...) talvez eu não chegasse a ir mais que uma vez na cozinha. Então, eu acho que a professora tem que resolver o problema, a direção... Se a direção não quisesse, a professora teria que ir atrás dos pais, mobilizar. $O$ aluno sem comida, não dá. Eu não imagino uma aula e o aluno com fome. Eu não ia nem na Delegacia (de Ensino) e resolvia ali mesmo. (O que faria na Delegacia?) Eu iria fazer um comentário, relataria a situação ocorrida e se, caso a Delegacia cruzasse os braços (.... eu ia no Magdalena (programa de rádio); se o Magdalena não resolvesse, eu ia no Ratinho (programa de TV); se o Ratinho não resolvesse, eu me suicidava. Não, aí eu não ia dar aula depois do recreio. Seria a última instância. Vamos supor que todas as instâncias não fossem resolvidas, eu cruzaria os braços, eu não daria aula. Ficaria lá, a gente ia ficar embaixo da árvore recuperando o sono. Beber água e dormir. (Tereza, 47; 20)

Nível III. Profissionalidade refletida: apresenta como traços básicos o exercício profissional refletido, a autonomia responsável e a identidade profissional.

No plano pedagógico, o nível III caracteriza-se também pela flexibilidade da prática, como no nível anterior, mas essa flexibilidade mostra-se de outra natureza: a adequação da matéria programada ao ritmo de aprendizagem e às peculiaridades dos alunos concretiza-se após análise da situação; a experimentação de materiais didáticos se faz de maneira criteriosa; os procedimentos são alterados em razão de dados analisados e de justificativas fundamentadas. Já não se notam rigidez e automatismos, tampouco ambigüidades e experimentações cegas. Exemplos: 
(Rotina) (Avaliação geral) Isso aí a gente sente que a $5^{\text {a }}$ série é especial, não pode pegar o padrão de outra série (...) ○ professor tem que ser realmente um artista, a cada platéia ele tem que agir diferente, também. Até o modo de eu falar com a $5^{\text {a }}$ tem que ser diferente (...) Até de $7^{\text {a }}$ pra $7^{\text {a }}$. Tem $7^{\text {a }}$ que são imaturos. Eu acho que esquema é furado. (Meire, 39; 13)

(Rendimento) (Como avalia a situação?) Nem todos os alunos de (disciplina da entrevistada) da escola são meus alunos. Agora, 50\% da classe indo mal, eu tenho que rever tudo o que estou fazendo - o conteúdo, o porquê que ele não está entendendo. Porque eu vejo a falha é na gente mesmo, eu não fujo disso. Tem aluno que não quer estudar, acabou, não quer. Mas 50\% não entenderem algo que você explicou, e não irem bem, alguma coisa está acontecendo. Vou ter que fazer uma auto-análise nos meus métodos, onde eu estou falhando. E 50\%, claro, é o interesse do aluno, também. ( $\bigcirc$ que a professora deveria fazer com a matéria que havia programado?) Pode rever, que ela está falhando também. É aquela parada que eu dou, eu paro tudo. E mesmo assim, escapa muita coisa. (E com o livro didático escolhido?) $\bigcirc$ livro é mais um referencial para o aluno não se sentir perdido. Exercício de livro eu raramente uso. Eu faço os meus próprios exercícios. Eu não descarto o livro didático. Acho que é um referencial, um instrumento de pesquisa. É rever o livro, fazer uma leitura séria (...) mas não pode ser Bíblia. A não ser que você tenha um esquema pra usar algumas páginas do livro, também. Pode usar pra pesquisa. (Meire, 39; 13)

Quando se trata de problemas ligados à gestão da classe, estão ausentes as soluções heterônomas. Podem manter-se, ainda, medidas repressivas, principalmente em sua forma pontual, mas predominam as soluções investigativas e a busca de alternativas inovadoras, sem que o professor deixe de atentar para as particularidades de comportamento dos alunos e para as suas razões. Na gestão da matéria, também não se notam medidas heterônomas. $\bigcirc$ tratamento de problemas de incompreensão do aluno, do seu baixo rendimento, ou de dificuldade específica de aprendizagem, pode incluir medidas reiterativas/remediadoras, mas se notam, com maior freqüência, soluções inovadoras.

Em qualquer caso, porém, o tratamento do problema é submetido à reflexão, ao comprometimento do professor com os alunos e à responsabilidade pelo próprio trabalho e papel. Sucessos e fracassos do aluno não mais se ligam diretamente a situações observáveis, puramente perceptíveis. Exemplos:

(Indisciplina) (Como avalia a situação?) Não é freqüente nem na $5^{\text {a }}$ série. No começo do ano (...) tenho um bate-papo muito longo com ele, pode durar até um mês, pra ele me conhecer. - "Essas são as regras do jogo". O primeiro contato é muitíssimo importante. Ele me conhece, eu me exponho a ele como profissional, eu me abro, o que sinto na minha profissão eu coloco, o quanto que eu gosto de dar aula, 
o quanto aquilo é importante pra mim. Então, eu deixo ele me conhecer. Ponho as regrinhas. $\mathrm{Na} 6^{a}$ já não preciso falar, na $7^{\mathrm{a}}$... Tenho atividades pra todos os dias, já me planejo antes. Ele nunca vai ficar sem fazer nada. (...) $\bigcirc$ que eu acho: o professor tem todos os recursos pra resolver o problema em sala de aula. Ele mostra para o aluno que é capaz de resolver os problemas. Não requer intervenção do inspetor de alunos ou da direção. Não é brigar com o aluno, é aproveitar o tempo dele. A direção é para o último caso, isso não é uma situação grave que requeira intervenção da direção. (Meire, 39; 13)

(Motivação) (O que a professora poderia fazer...?) Dou outras atividades - pode não ter nada a ver com o conteúdo. Peço para fazer coleções, colocar em ordem, arrumar as revistas pra mim, os vidros. Mas eu vou cobrar o conteúdo deles. É facilmente administrável - depois de você ver que o problema não está em você. Mas você tem que ter uma gama muito grande de atividades pra desenvolver com eles. Eu tenho, eu sou sincera. Se ele não está a fim de estudar naquele momento, não vai fazer o que ele quer, mas o que eu quero (...) (Precisaria de ajuda?) Não, não é grave, só caso grave que é pra ir pra direção, que extrapola todos os limites. Porque nada me irrita, assim, de coisinhas de alunos. Eu falo pra eles: - "Eu estou aqui, me explora (...)", quando eu vejo que a coisa não vai. (Meire, 39; 13)

Todos esses traços significam descentração de perspectiva, ao mesmo tempo que alargamento do referencial de análise e interpretação. Ressaltam-se, portanto, de um lado, a tomada de consciência da própria ação e, de outro, a compreensão da conduta do aluno, pois o registro de observáveis constatados no aluno tem efeito retroativo sobre a ação docente, que acaba por alterar-se. A tomada de consciência é, então, facilitada pela introdução de regulagens ativas, que permitem o exercício refletido da prática. Exemplo:

(Rotina) (Como explicaria essas condutas inadequadas?) É o contato, o adolescente que está adolescendo, ele tem necessidade de atenção. Às vezes, a pergunta babaca dele é uma maneira de dizer: - "Eu estou aqui" (...) Se eu quero um aluno crítico, na hora que critica eu repreendo? O mais preocupante é o aluno apático. (Por que será que eles não entendiam a matéria?) É difícil responder impessoalmente. Eu fico muito frustrada quando o aluno não aprende. Eu sempre tenho o olho em mim. Se eu detecto isso, ainda posso sanar. $\bigcirc$ mais grave é se acho que estão aprendendo e não estão. E isso ocorre. Tanto é que eu mudo sempre. (Meire, 39; 13)

exercício profissional refletido mostra-se, também, na análise de como e por que as condições presentes constituem-se em barreiras à autonomia do professor. As tomadas de decisão baseiam-se, desse modo, na reflexão e podemos dizer que a profissionalidade refletida segue os princípios do dever autônomo (Piaget, 
1994). Em situações de possível confronto interpessoal, o conflito na verdade deixa de existir, desde que é assimilado a uma visão integrada da situação, na qual se salientam não apenas o direito do outro, como também o direito e a legitimidade da ação profissional. Não se notam, portanto, reações de negação, afastamento ou de evitar o conflito, presentes em níveis anteriores. Exemplos:

(Conflito professor-alunos) (Quem teria razão?) Ela não está certa, mas os alunos não podem ser insubordinados. Não podem achar que eles podem fazer qualquer coisa. Eu não posso dizer que eles estão certos. (Então nenhum dos dois tem razão?) Não, não é nenhum dos dois tem razão. Ela não pode agir dessa maneira (...) punitiva, com prova. (...) Eu, (Meire), estaria errada, mas os alunos não podem agir dessa maneira comigo, eles não devem. É uma questão de posicionamento dentro da sala, o professor é que limitou, delimitou o espaço dele (...) Não posso dizer que a professora está certa. Muito mais errado está o aluno de não atender à professora, porque daí ela nunca mais vai conseguir lidar com essa classe. ( $\bigcirc$ professor diz que foi feita revisão da matéria e os alunos, que a prova não foi marcada... E então?) Mas não tem que marcar prova! Tudo... É aquilo que você fala para o aluno: -“Todo dia é dia de aprender, de estudar". (...) Ela pode pedir a hora que ela quiser, se ela está confiante naquilo que fez. Mas não assim, como represália. (Meire, 39; 13)

(Conflito professor-diretor) (Quem teria razão nessa história?) Não é razão. Ela (diretora) tem razão de reclamar do excesso, mas eu acho que tem jeito de resolver, sem que a professora tenha que mudar o estilo de aula dela (...) Dá para chegar num ponto comum com a diretora. (E se fosse um colega a reclamar?) Se o colega não soubesse o que o professor está fazendo e reclamasse por reclamar do baruIho, ele não teria razão. Ele poderia pedir, conversar... Tem razão de reclamar do barulho, sim, mas tem que ver o que está sendo desenvolvido, e chegar num acordo. (Quanto à solução, a professora deveria) reorientar seus alunos quanto às atividades e como desenvolvê-las. Salientando a importância da atividade dela, que é importante, mas que os outros têm que ser respeitados, que a direção tem que ser respeitada, também, do barulho. (Reorientar como?) Colocar algumas regrinhas básicas quanto ao volume da voz, aos grupos, discutirem de uma maneira não tão exaltada. Aproveitar e falar sobre a poluição sonora, que isso atrapalha, também, que ninguém aprende num ambiente de muita excitação e bagunça. (Meire, 39; 13)

A conquista da autonomia acompanha-se de uma identidade profissional relativamente estável. Já não se notam traços de confusão ou fragmentação de identidade e o professor não aceita desvio de função. $O$ sentimento de pertença a uma categoria profissional impede a atitude preconceituosa com relação a colegas que, por força de vieses institucionais, estão hierarquicamente posicionados em situação inferior. Resultam daí as relações cooperativas (e não mais de coação) e a consciên- 
cia de responsabilidade conjunta pela função docente, percebida como comum a professores enquanto pertencentes a um corpo coeso de profissionais do ensino. As soluções tornam-se, então, políticas e cooperativas. Exemplos:

(Merenda) (Ao invés de trazer a merenda, o que o professor poderia fazer?) Deveria haver uma pressão sobre os órgãos pra se apurar o que realmente estava acontecendo. Eu acho que realmente é essa ação política, que envolvesse a escola, os pais, que envolvesse passeatas, manifestação, com atos públicos, através da imprensa ou através de associações de bairro (...) É difícil prover a casa, imagine prover a escola! Acho que o caminho é o político. (E faltando a merendeira...?) É mais fácil, é o caso de mau funcionário. Então, a pessoa responsável já estaria ali pra conversar com ela. (E se a professora fosse fazer a merenda...?) Não acho certo, porque não é a função dela. Cada um na escola tem a sua função e deve exercer a sua função. (Renata, 37; 14)

(Conflito entre colegas) (Como resolver o impasse?) Isso deve ser comentado: "Notei isso, eu acho que deveríamos trabalhar pra que ele melhorasse, não ficasse tão angustiado quanto a essa questão". Eu acho que todo mundo deve tratar do aluno, deve tentar fazer ele superar isso. Mas não é culpa da disciplina da entrevistada, nem de Matemática. Hoje em dia se fala em vários métodos, apesar de que aprendemos pelo método tradicional (...) O professor deveria procurar ter um curso, ou uma especialização (...) ele deveria ter uma ajuda acadêmica para poder se munir meIhor de material - te dá os meios. (De qual professor você fala?) Acho que todos (precisam) de atualização. (Renata, 37; 14)

\section{CONCLUSÕES}

Uma primeira conclusão que se pode tirar dos dados obtidos com esta pesquisa é a de que a mudança da prática profissional do professor parece ter dois requisitos: sensibilização com relação aos fatores perturbadores centrais do equilíbrio atingido, que nem sempre são percebidos, e sensibilização do professor à própria mudança. $\bigcirc$ professor pode perceber o conflito, sem que seja sensível à mudança, e pode sensibilizar-se a mudar, mas sem que saiba como fazê-lo.

Tendo em vista que as mudanças observadas se ordenam em uma hierarquia de níveis, a seqüência estabelecida difere das apresentadas por outros autores (por exemplo, Berliner, 1988; Cavaco, 1995; Huberman, 1995; Lidstone, Hollingsworth, 1992), à medida que parece seguir um certo caminho que insinua que um processo equilibrador está regulando pensamento e ação docentes, sem desvios de rota significativos. Os níveis que encontramos não parecem obedecer, simplesmente, 
ao critério de idade cronológica, nem comportam, meramente, estilos de aprender a ensinar.

Alguns autores mencionam o fato de que o pensamento prático dos professores não pode ser ensinado, mas pode ser aprendido mediante reflexão na e sobre a ação (veja-se, por exemplo, Pérez Gómez, 1992). Mas talvez todos concordem com os benefícios e a validade das trocas de experiências e saberes entre professores.

A esse respeito, podemos apontar a presença de dois círculos viciosos, não percebidos pelos autores que defendem a prática reflexiva, a indagação na ação e a interação entre pares. Por um lado, quando o professor permanece na reflexão na e sobre a ação, isso resulta apenas na construção de teorias em ação personalizadas e sobre situações singulares, com pouca possibilidade de generalização. Por outro, se o caráter público dos conhecimentos próprios do ensino permanecer dependente de trocas casuais entre professores, tendo por base apenas suas experiências individuais e as trocas informais, o repertório resultante não comportará a validade necessária à sua transmissão. É necessário que o "público" seja cientificamente validado e organizado de modo sistematizado em teorias da ação (e não teorias em ação) - tarefa que cabe à pesquisa científica.

Ao que parece, fatores tais como mudanças nas exigências sociais, imposições burocrático-administrativas e desvalorização da profissão são os maiores obstáculos ao denvolvimento da profissionalidade refletida, cuja aquisição é obra coletiva, dentro de um contexto social e escolar.

Discursos que tomam o professor como prático reflexivo parecem avançados, mas podem estar obscurecendo o contexto real em que se desenvolve a ação docente. Deve ser lembrado que as margens de autonomia dos professores estão delimitadas por diretrizes políticas e pela realidade histórica e ideológica, condicionadoras da profissionalidade. Seria muito mais conveniente levantar a voz contra certa prática nefasta de instituir, periodicamente, pacotes educacionais raramente bem-vindos e sem qualquer continuidade e, às vezes, sem nexo também.

Acreditamos, enfim, que os professores não podem ficar sós na realização das tarefas de indagação, reflexão e trocas, pois nem sempre eles se mostram sensíveis a problemas e conflitos que são centrais na profissão docente. Há que sensibilizá-los "de fora". Eis, portanto, um dos papéis fundamentais da universidade: sensibilizar os professores, em sua formação inicial e também continuada, para os problemas e os contextos do ensino. 


\section{REFERÊNCIAS BIBLIOGRÁFICAS}

BERLINER, D. C. Implications of studies of expertise in pedagogy for teacher education and evaluation. In: THE 1988 ETS INVITATIONAL CONFERENCE. Directions for Teacher Assessment. proceedings of ... Princeton, New Jersey: Educational Testing Service, 1988, p.39-67.

BODER, A. Esquema familiar: a unidade cognitiva de procedimento preferida. In: INHELDER, B.; CELLÉRIER, G. et al. O Desenrolar das descobertas da criança: um estudo sobre as microgêneses cognitivas. Porto Alegre: Artes Médicas, 1996, p. 186-211.

CATTANI, A. D. Trabalho e autonomia. Petrópolis: Vozes, 1996.

CAVACO, M. H. Ofício do professor: o tempo e as mudanças. In: NÓVOA, A. (org.). Profissão professor. Porto: Porto Editora, 1995.

CHAKUR, C. R. de S. L. Desenvolvimento profissional docente: contribuições de uma leitura piagetiana. Araraquara: JM, 200I.

Níveis de construção da profissionalidade docente: um exemplo com professores de $5^{\mathrm{a}}$ a $8^{\mathrm{a}}$ séries. Cadernos CEDES. Campinas, n. 36, p.77-93, 1995.

Prática docente: construindo o processo. In: BICUDO, M. A. V.; BERNARDO, M. V. C. (orgs.). Núcleos de ensino: um projeto de educação continuada. São Paulo: Editora Unesp, 1996, p. I03-119.

(coord.). Alternativas à prática pedagógica nas séries finais do 10 grau. Araraquara: Unesp/Fac. Ciências e Letras, 1990. [Relatório de Pesquisa]

. (coord.). Alternativas à prática pedagógica nas séries finais do 10 grau - II. Araraquara: Unesp/Fac. Ciências e Letras, 1991. [Relatório de Pesquisa]

(coord.). Prática pedagógica: construindo, experimentando e avaliando o processo. Araraquara: Unesp/Fac. Ciências e Letras, 1993. [Relatório de Pesquisa]

CLANDININ, D. J. Personal practical knowledge: a study of teachers' classroom images. Curriculum Inquiry, v. I 5, n. 4, p.361-385, 1985.

DOMAHIDY-DAMI, C.; LEITE, L. B. As provas operatórias no exame das funções cognitivas. In: LEITE, L. B. (org.). Piaget e a escola de Genebra. São Paulo: Cortez, 1987. p. I I I I 23.

FURTH, H. G. The World of grown-ups: childrens' conceptions of society. New York: Elsevier, 1980.

GARCíA, C. M. A formação de professores: novas perspectivas baseadas na investigação sobre o pensamento do professor. In: NÓVOA, A. (coord.). Os Professores e a sua formação. Lisboa: Dom Quixote, 1992. 
GIOVANNI, L. M. A Didática da pesquisa-ação: análise de uma experiência de parceria entre universidade e escolas públicas de $1^{\circ}$ e $2^{\circ}$ graus. Tese (Dout.) - Universidade de São Paulo, Faculdade de Educação, São Paulo, 1994.

HUBERMAN, M. O ciclo de vida profissional dos professores. In: NÓVOA, A. (org.). Vidas de professores. Porto: Porto Editora, 1995, p.31-61.

IMBERNÓN, F. La Formación y el desarrollo profesional del profesorado: hacia una nueva cultura profesional. Barcelona: Graó, 1994.

INHELDER, B.; DE CAPRONA, D. Rumo ao construtivismo psicológico: Estruturas? Procedimentos? Os dois 'indissociáveis'. In: INHELDER, B. et al. O Desenrolar das descobertas da criança: um estudo sobre as microgêneses cognitivas. Porto Alegre: Artes Médicas, 1996, p.7-37.

LAMPERT, M. How do teachers manage to teach? Perspectives on problems in practice. Harvard Educational Review, v. 55, n. 2, p. 178-194, 1985.

LIDSTONE, M. L.; HOLLINGSWORTH, S. A longitudinal study of cognitive change in beginning teachers: two patterns of learning to teach. Teacher Education Quarterly, v. 19, n. 4, p.39-57, 1992.

NÓVOA, A. Les Enseignants: à la recherche de leur profession. European Journal of Teacher Education, v. 17. n. I/2, p.35-43, 1994.

Formação de professores e profissão docente. In: (coord.). Os Professores e a sua formação. Lisboa: Dom Quixote, 1992.

Passado e o presente dos professores. In: (org.). Profissão professor. 2 ed. Porto: Porto Editora, 1995, p. 13-34.

PACHECO, J. A. O Pensamento e a acção do professor. Porto: Porto Editora, 1995.

PÉREZ GÓMEZ, A. I. O Pensamento prático do professor: a formação do professor como profissional reflexivo. In: NÓVOA, A. (coord.). Os Professores e a sua formação. Lisboa: Dom Quixote, 1992, p.93-।14.

PIAGET, J. L'Équilibration des structures cognitives: problème central du développement. Paris: PUF, 1975.

O Juízo moral na criança. São Paulo: Summus, 1994.

A Representação do mundo na criança. Rio de Janeiro: Record, s/d.

. A Tomada de consciência. São Paulo: Melhoramentos, 1977.

SHAVELSON, R. J.; STERN, P. Research on teachers' pedagogical thoughts, judgments, decisions, and behavior. Review of Educational Research, v. 5 I , n. 4, p.455-498, I 981. 
SCHÖN, D. A. La Formación de profesionales reflexivos: hacia un nuevo diseño de la enseñanza y el aprendizaje en las profesiones. Barcelona: Paidós, 1992a.

.Formar professores como profissionais reflexivos. In: NÓVOA, A. (coord.). Os Professores e a sua formação. Lisboa: Dom Quixote, 1992.

ZABALZA, M. A. Diários de aula (contributo para o estudo dos dilemas práticos dos professores). Porto: Porto Editora, 1994.

ZEICHNER, K. M. A Formação reflexiva de professores: idéias e práticas. Lisboa: Educa, 1993.

Novos caminhos para o practicum: uma perspectiva para os anos 90 . In: NÓVOA, A. (coord.). Os Professores e a sua formação. Lisboa: Dom Quixote, 1992, p.115-138.

ZEICHNER, K. M.; LISTON, D. P. Teaching student teachers to reflect. Harvard Educational Review, v. 57, n. I, p.23-48, 1987.

Recebido em: junho 2002

Aprovado para publicação em: julho 2002 